$r \cdot 1$.

\title{
Effects of menopause on serum oxidant status and lipid profile in Mosul city
}

\author{
Bassam N. Aziz
}

Department of Anaesthesis, Mosul Technical Institute, Iraq

\begin{tabular}{ll} 
Received: & Accepted \\
\hline ro.1.r... & rr.1.r..9
\end{tabular}

\begin{abstract}
Objectives: To study the effect of menopause associated with estrogen deficiency on lipid peroxidation products, such as malondialdehyde (MDA) with evaluation of some antioxidants like, glutathione (GSH) and its relation to lipoprotein levels in women living in Mosul City.

Design: Case-control study.

Setting: The study was carried out in Al-Salam Teaching Hospital in Mosul City, during the period from January $r \cdots \wedge$ to April $r \cdots \wedge$.

Patients and Methods: A total of $r v$ women aged $r \cdot-\varepsilon \circ$ years were reported to be premenopausal and $\leqslant r$ women aged $\leqslant 0_{-} \uparrow$. years were recorded to be postmenopausal. Blood samples were collected for both groups. The assessments of serum malondialdehyde (MDA), glutathione (GSH), estrogen, arylesterase, calcium, total cholesterol, triglycerides (TG), low-density lipoprotein cholesterol (LDL-C), and high-density lipoprotein cholesterol (HDL-C) were done.

Results: There were significant increase in MDA level in women after menopause in comparison with premenopausal age. On the other hand, GSH, estrogen, arylesterase, and calcium levels were significantly decreased. In respect to lipids, total cholesterol, TG, and LDL-c, were significantly increased in opposite to HDL-c, in which was decreased significantly in postmenopausal women in relation to premenopausal subjects.

Conclusion: The increase of MDA and the decrease of antioxidants concentrations like gluthathione, estrogen and HDL-C in postmenopausal women could contribute to acceleration of the cellular oxidative damage.
\end{abstract}

Keywords: Menopause, oxidative stress, antioxidants, malondialdehyde.

$$
\begin{aligned}
& \text { الخلاصة }
\end{aligned}
$$

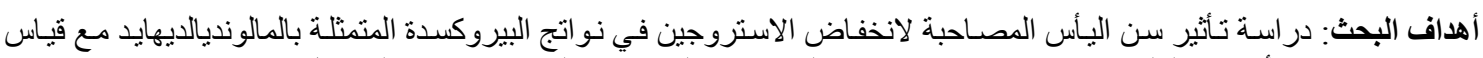

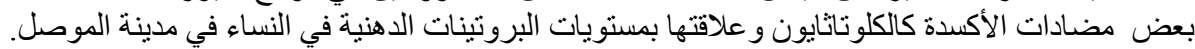

$$
\begin{aligned}
& \text { التصميم: دراسة عينية مقارنة. }
\end{aligned}
$$

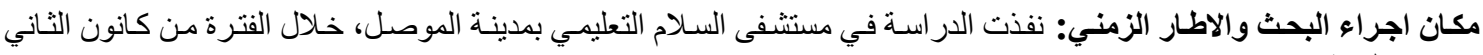

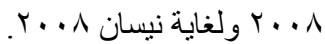

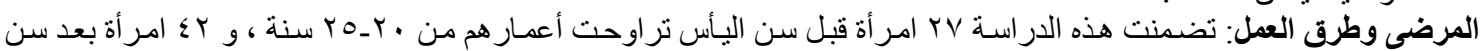

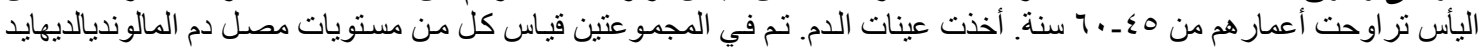

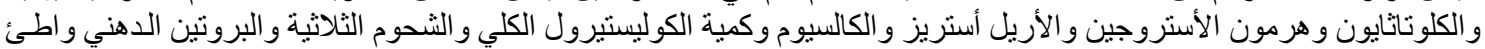

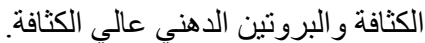

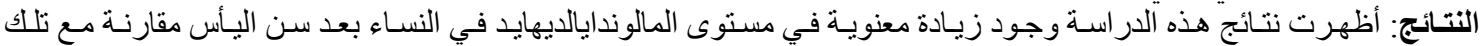

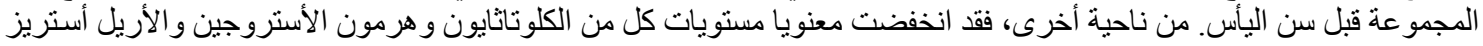

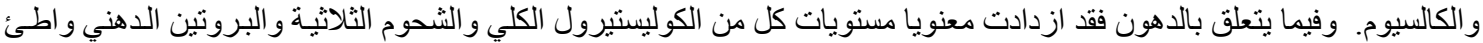

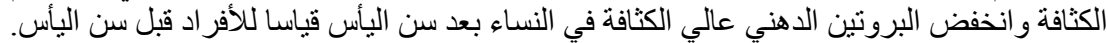

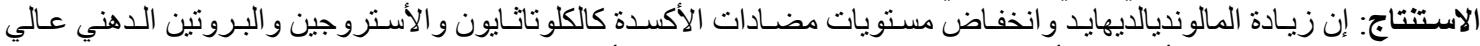

$$
\begin{aligned}
& \text { الكثافة في النساء بعد سن اليأس يمكن أن يساهم في تعجيل التخريب الخلوي التأكسدي. }
\end{aligned}
$$


$\mathrm{M}$

enopause is the time in a woman's life when her period stops. It usually occurs naturally, most often after the age of $\leqslant 0$. Menopause happens because the woman's ovary stops producing the hormones estrogen and progesterone.

The relative estrogen deprivation in postmenopausal women is associated with physiological changes and increased risk of several diseases, including cardiovascular diseases.' Estrogen has beneficial effects on the lipid profile, such a significant elevations in high density lipoprotein cholesterol and reductions in low density lipoprotein cholesterol reported. ${ }^{r}$ However, the available evidence suggests that in vivo physiological concentrations of estrogen may have a modest antioxidant activity.

Oxidative stress has been implicated in the pathogenesis of ageing and menopause, and can arise through the increased production of lipid peroxides representing by malondialdehyde (MDA) level and/or a deficiency of antioxidant defense." On this bases, and because there are no previous reports concerning MDA levels in postmenopausal women related to premenopausal age; the study was planned to investigate the effects of the menopause on serum MDA concentration and antioxidants, including estrogen level and glutathione, in addition to lipid profile parameter in women living in Mosul City.

\section{Subjects and methods Experimental Design}

A total of $r v$ women aged $r \cdot-\leqslant 0$ years were reported to be premenopausal and $\leqslant r$ women aged $\leqslant 0-\tau$. years were recorded to be postmenopausal from January $r \ldots \wedge$ to April $r . . \wedge$. Informations on menopausal status was based on self-report. Women who were premenopausal were asked whether their menstrual periods had stopped during the past year and, if yes, when their last period was and what the reason was (naturally, by surgery, or by radiation/medication). Generally, the onset of natural menopause was defined as the age at the last menstrual period prior to stopping menstruation for ir months. Accordingly, women who had undergone a spontaneous menopause as demonstrated by amenorrhea volunteered to participate in this study as postmenopausal women.

This study was conducted in Al-Salam Teaching Hospital, Mosul City, and approved by the local institutional review board, and all of the participants provided written informed consent. None of the patients had a history of previous hormone replacement therapy, and smokers, diabetics, patients with chronic inflammatory conditions, hepatic or respiratory disease, and those on antioxidants, vitamin or other medication were excluded from the study. Each woman underwent a comprehensive history and physical examination including a standard electrocardiogram.

\section{Blood sampling and analysis}

All blood samples were collected after a IY-hour overnight fast. Venous blood samples from each woman obtained from the antecubital vein between $\wedge_{-} 11$ a.m. was drawn into plain test tubes. After centrifugation of the blood for 10 minutes at $\mathrm{r} . . \mathrm{g}$, the serum obtained was stored in several aliquots at $-r_{0}$ $C^{\prime}$ until assay. The readings of the measured parameters were done at clinical biochemical laboratory in Mosul Technical Institute.

\section{Oxidant-antioxidant serum capacity}

To assess the association between lipid peroxidation and the menopause, the level of serum MDA was determined by a modified procedure using the thiobarbituric acid reaction substance (TBARS) methods." Serum glutathione (GSH), on the other hand, was determined by a modified procedure utilizing Ellman`s reagent.'

\section{Serum estradiol}

Estrogen hormone was analyzed by MINIVIDAS analyzer for the quantitative measurement of I $v \beta$-estradiol in serum, using the ELFA technique (Enzyme Linked Fluorescent Assay).

\section{Serum calcium}

Serum total calcium was determined colorimetrically, without deproteinization, using a kit purchased from Syrbio (Cat No. $r \leqslant \cdot r$ ). The absorbance of standard and samples against blank were measured at $7 / \mathrm{r} \mathrm{nm}$.'

\section{Measurement of arylesterase_activity}

Measurement of arylesterase activity in serum was performed using the colorimetric method at $\mathrm{rV} \cdot \mathrm{nm}$.

\section{Serum lipid profile}

Serum levels of total cholesterol,' triglycerides (TG), ${ }^{1 r}$ and high-density lipoprotein cholesterol (HDL-c) $)^{\text {w }}$ were measured by enzymatic colorimetric methods with a spectrophotometer according to the manufacturer instructions. The concentration of low density lipoprotein cholesterol (LDL-c) was calculated according to the following formula: ${ }^{10}$ 
Irq $J$ Pharm Vol. ${ }^{9} \& 1 \cdot$, No. ',

$r \cdot 1$.

$\mathrm{C} L D L=\mathrm{C}$ serum $-\mathrm{C} \mathrm{HDL}-\mathrm{TG} /{ }^{\circ}$

Where, $\mathrm{C}=$ concentration of cholesterol in LDL, HDL, in serum, expressed in $\mathrm{mg} / \mathrm{dl}$.

$\mathrm{TG}=$ serum triglycerides concentration, expressed in $\mathrm{mg} / \mathrm{dl}$

\section{Statistical analysis}

Data are presented as mean \pm standard deviation of the mean (SDM). Statistical analysis was performed by IndependentSamples t-test with SSPS version $1 .$. software. A value of $\mathrm{P}<\cdot \ldots+$ indicates statistical significance. '"

\section{Results}

Oxidants-antioxidant capacity of serum

The effect of menopause on lipid peroxidation by-product, MDA is shown in Figure !. Menopause produced significant increase

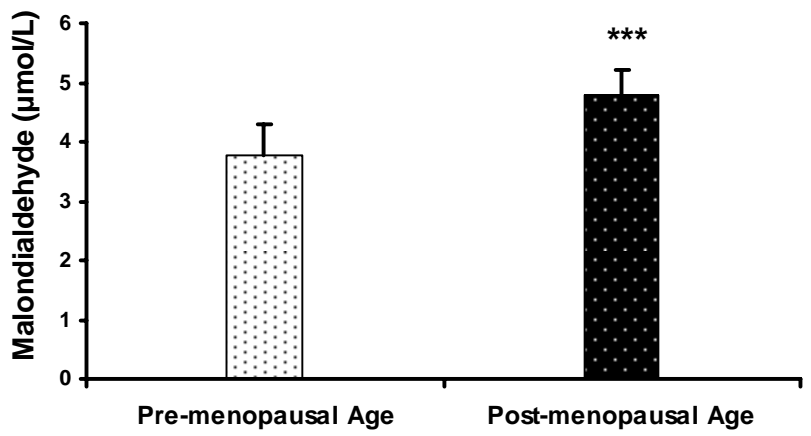

$(P<\cdot, \cdot 1)$ in MDA concentration when compared with premenopausal women. On the other hand, women after menopause showed significant decrease $(P<\cdot, \cdots)$ in glutathione content in comparison with those before menopause, as shown in Figure '.

\section{Estrogen and associated factors}

The levels of measured parameters, estrogen, arylesterase, and calcium of both groups before and after menopause are depicted in table 1. Serum estrogen, arylesterase, and calcium levels of the women in the study group after menopause were significantly lower $(\mathrm{P}<\cdot, \cdots)$ than in the other before menopause.

Figure 1. Effect of Menopause In Malondialdehyde (a) and Glutathione Level (b). Data are means \pm SD from $r V$ women for pre-menopausal age, and $\leqslant r$ women for post-menopausal age. The stars on histograms indicate significant difference at $\mathrm{p} \leq \cdot \cdots$ '.

Table 1: Effects of Menopause In Estrogen Level And It's Related Factors.

\begin{tabular}{|c|c|c|c|}
\hline${ }^{-}$Parameters & Estrogen & Erylesterase & Calcium \\
\hline Treatments & $(\mathrm{pg} / \mathrm{ml})$ & $(\mu / \mathrm{ml})$ & $(\mathrm{mmol} / \mathrm{L})$ \\
\hline $\begin{array}{l}\text { Pre-Menopausal Age } \\
\qquad(n=r v)\end{array}$ & $r) . T \pm \varepsilon . r r r$ & (b) & $r . r \mid \cdot T V$ \\
\hline $\begin{array}{l}\text { Post-Menopausal Age } \\
\qquad(\mathrm{n}=\varepsilon r)\end{array}$ & $\begin{array}{c}* * * \\
1 \leq .01 \pm 1.191\end{array}$ & $\begin{array}{c}* * * \\
\wedge \tau . \leqslant 9 \pm \tau . \leqslant Y)\end{array}$ & 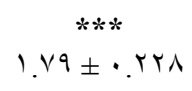 \\
\hline
\end{tabular}

- Values are expressed as means $\pm \mathrm{SD}$.

- $* * *$ Significantly different as compared with respective control at $(\mathrm{p}<\bullet . \cdots)$ 
Table r: Effects of Menopause In Lipid Profile

\begin{tabular}{|c|c|c|c|c|}
\hline Parameters & $\begin{array}{c}\text { Total } \\
\text { Cholesterol }\end{array}$ & Triglyceride & $\begin{array}{l}\text { Low-Density } \\
\text { Lipoprotein } \\
\text { Cholesterol }\end{array}$ & $\begin{array}{l}\text { High-Density } \\
\text { Lipoprotein } \\
\text { Cholesterol }\end{array}$ \\
\hline Treatments & $(\mathrm{mmol} / \mathrm{L})$ & $(\mathrm{mmol} / \mathrm{L})$ & $(\mathrm{mmol} / \mathrm{L})$ & $(\mathrm{mmol} / \mathrm{L})$ \\
\hline $\begin{array}{l}\text { Pre-Menopausal Age } \\
\qquad(\mathrm{n}=r v)\end{array}$ & $\varepsilon . V \pm . .071$ & $\perp . r \cdot \pm \cdot .1 \wedge V$ & $r .49 \pm .001$ & $\cdot \wedge \uparrow \pm \cdot \cdots \wedge$ \\
\hline $\begin{array}{l}\text { Post-Menopausal Age } \\
\qquad(\mathrm{n}=\varepsilon r)\end{array}$ & $\begin{array}{c}* * * \\
7 . r+.0 V r\end{array}$ & $\begin{array}{c}* * * \\
\text { r.VA } \pm \cdot .01 r\end{array}$ & $\begin{array}{c}* * * \\
0 . Y 7 \pm .07 V\end{array}$ & $\begin{array}{c}* * * \\
.7 \pi \pm \cdot . \cdot v\end{array}$ \\
\hline
\end{tabular}

- Values are expressed as means \pm SD.

- $\quad * * *$ Significantly different as compared with respective control at $(\mathrm{p}<\bullet . \cdots)$

\section{Lipid profile}

Serum lipids are reported in Table $r$. In postmenopausal women, serum total cholesterol, TG, and LDL-c levels were significantly higher $(p<\cdot . \cdot)$ than in premenopausal women. Conversely, HDL-C level was decreased significantly in postmenopausal women when compared with women before menopause.

\section{Discussion}

The higher prevalence of diseases in postmenopausal women could be related to an increased oxidative stress, which is due to unbalanced pro-oxidant/antioxidant

Equilibrium." As a consequence of oxidative stress, lipid peroxidation (a major indicator of oxidative stress) can occur. ${ }^{\text {'v }}$ In this study, measured serum MDA as a marker of free radical-mediated lipid peroxidation. MDA was increased significantly after menopause compared to premenopausal levels. This is in line with results by Asada et al. ${ }^{\wedge}$ which showed that serum lipid peroxide levels of normal premenopausal women were lower than those of normal postmenopausal women, and that bilateral ovariectomy significantly increases serum lipid peroxide in premenopausal women.

On the other hand, a significant decrease in serum GSH concentration was noticed in women after menopause in comparison with premenopausal age. This indicates the presence of oxidative status, which may alter a variety of cell body functions. $^{19}$ The alterations of serum GSH system components in women after menopause may be in part explained by the changes in the GSH-related enzyme levels. Lipid peroxides are quickly metabolized to a less toxic hydroxy derivative by glutathione peroxidase (GSH-PX), which uses glutathione as a proton donor to reduce hydrogen peroxide to water with the production of glutathione disulfide (GSSG). GSSG is recycled back to $\mathrm{GSH}$ by glutathione reductase using $\mathrm{NADPH}$ from the hexose monophosphate shunt. (Figure r). ${ }^{r \cdot}$

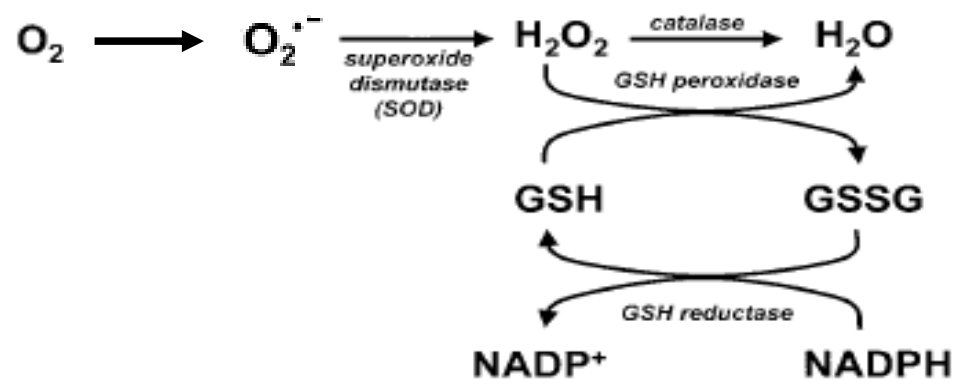

Figure r: Pathways of reactive oxygen species (ROS) production and clearance. GSH, glutathione; GSSG, glutathione disulfide. ${ }^{\text {. }}$ 
Estrogens, like GSH, have a substantial capacity to inhibit lipid peroxidation caused by free radicals." Therefore, estrogen has been reported to have antioxidant capabilities,' and the circulating concentrations of estrogen decreased, as reported in the present study. The relative estrogen deprivation in postmenopausal women is associated with physiological changes and increased risk of several diseases, including cardiovascular disease, which is presumably mediated through increased oxidative stress as assessed by the enhanced free radical superoxide production in the vessel wall. ${ }^{r}$

The study of the present work was supported by Massafra et al. ${ }^{r}$ who suggested that a lack of ovarian estrogen production in women with amenorrhoea, was associated with reduced protection against oxidative stress.

One of the most important factor that make to facilitate the anti-oxidative action of estrogen and high density lipoproteincholesterol is arylesterase/Paraoxonase enzyme. ${ }^{r \xi}$ To be able to function as potential antioxidants, estrogens first need to be converted to estrogen esters in a reaction catalyzed by plasma lecithin/cholesterol acyltransferase. After esterification, estrogens are able to incorporate in the lipoprotein particles. By this way, estrogen could provide antioxidant protection.

Human serum arylesterase is able to hydrolyze lipid hydroperoxides and organophosphates which include neurotoxins that are widely encountered in the diet and household, $^{\text {ro }}$ and to delay or inhibit the initiation of oxidation induced by metal ions on lipoproteins. ${ }^{\Upsilon \top}$

In the present study, serum arylesterase enzyme activity was decreased in association with a significant decrease of estrogen level after menopause. Our findings are in good agreement with a recently published study that showed, a more potent reduction of serum arylesterase enzyme activity after surgical menopause, whereas estrogen replacement therapy reverses these effects. ${ }^{r v}$ Moreover, Sutherland et al. ${ }^{r \wedge}$ showed that arylesterase activity is abnormally low in postmenopausal women with type $r$ diabetes and increases during estrogen replacement therapy.

In addition to antioxidant action of estrogen, both estrogen and calcium have been shown to be beneficial in preventing osteoporosis in postmenopausal women Therefore, women over the age of $v \cdot y r$ are at greatest risk for osteoporotic fractures. ${ }^{\text {rq }}$
Estrogen replacement therapy (ERT), on the other hand, has been associated with slower bone loss, and reduced fracture incidence in postmenopausal women. ${ }^{r \cdot} \quad$ Calcium supplementation has also been shown to reduce bone loss in postmenopausal women. ${ }^{r}$ Furthermore, Prestwood et al. ${ }^{r r}$ demonstrated that treatment with a combination of these two agents may be more effective in preserving bone mass than treatment with either estrogen or calcium alone.

To further explore the role of estrogen on serum calcium level, Nordin et al. ${ }^{r r}$ suggested that estrogens promote tubular reabsorption of filtered calcium in postmenopausal women particularly in those with osteoporosis. Therefore, menopause has been shown to be accompanied by an increase in calciuria. ${ }^{r r}$ In addition, estrogen has been shown to stimulate the active form of vitamin $D_{1}, r_{\odot}\left(\mathrm{OH}_{r}\right) D_{r}$, which in turn increases calcium intestinal absorption. ${ }^{r \varepsilon}$ Moreover, calcium modulates estrogen metabolism, and increasing calcium intakes are associated with increasing concentrations of estrogen metabolites.

There have been few reports on a relationship between calcium deficiency and antioxidant enzymes. A reduction in calcium level in the present study after menopause, appears to be associated with a decrease in antioxidants such as glutathione. Unlike to the present study, Itoh et al. ${ }^{r}$ demonstrated that dietary calcium restriction increased the activities of certain antioxidant enzymes like superoxide dismutase (SOD), and GSH-PX in rat diaphragm but not of catalase. This suggests that dietary calcium restriction imposes oxidative stress in rat diaphragm.

The last part in this study concerned with lipid profile. In postmenopausal women, significantly increase in serum total cholesterol, TG, and LDL-c levels were observed in the present study. Conversely, HDL-c level was decreased significantly in postmenopausal subjects when compared with women before menopause.

Initial studies were done to determine the significance of the association of estrogens with lipoproteins on their antioxidant property. Cardiovascular disease is the leading cause of death in postmenopausal women over the age of $0 .{ }^{r}$ On the other hand, estrogen administration $^{r \wedge}$ caused a reduction in cardiovascular disease by $0 . \%$. At least part of the cardiovascular benefits of estrogens are mediated through changes in lipoproteins, ${ }^{r q}$ particularly by increases in high density lipoproteins (HDL). However, $v \circ \%$ of the beneficial effect of postmenopausal estrogen 
therapy is not due to improvements in circulating lipid levels but may involve antioxidant protection."

Recent studies have shown that estrogens inhibit oxidation of LDL-c in vitro and protect against DNA oxidative damage induced by hydrogen peroxide and arachidonic acid." This can be achieved by inhibiting the generation of superoxide radicals and at higher concentration can scavenge hydroxyl radicals. ${ }^{\text {¿r }}$

In contrast to LDL-c, Abplanalp et al. ${ }^{\text {r }}$ provide evidence that HDL could facilitate the antioxidant effect of estradiol- I $\vee(E r)$ through initial association, esterification and eventual transfer of Er esters to LDL. Furthermore, several lines of evidence suggest that the antioxidant effect of HDL is at least partially related to paraoxonase (PON), an enzyme associated with HDL surface (HDL-PON).

In conclusion, oxidative stress and oxidation of lipoproteins and membranes have been implicated in the development of many diseases and ageing. On the basis of the present study, it might be hypothesized that the increase of MDA and the decrease of antioxidants activity like GSH, estrogen and $\mathrm{HDL}$ in postmenopausal women could contribute to acceleration of the cellular oxidative damage.

\section{References}

l.http://www.nlm.nih.gov/medlineplus/menopa use.html

r. Schwenke DC. Aging, menopause, and free radicals. Semin Reprod Endocrinol. 199^; $17(\varepsilon): r \wedge)-r \cdot \Lambda$

r. Samaan SA, Crawford MH. Estrogen and cardiovascular function after menopause. J Am College Cardiol 1990;rT(T): $1 \leqslant \cdot r-$ $1 \leqslant 1$.

ะ. Vural P, Akgül C, Canbaz M. Effects of menopause and tibolone on antioxidants in postmenopausal women. Ann Clin Biochem r. .0; $\leqslant$ r:rr. -rrr.

- Nagata C, Takatsuka N, Kawakami N, Shimizu H. Association of diet with the onset of menopause in Japanese Women.

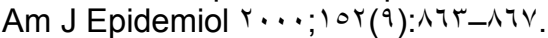

7. Delibasia T, Kockarb C, Celikc A, Kockard O. Antioxidant effects of hormone replacement therapy in postmenopausal women. Swiss Med Wkly r.. $7 ; 1+4: 01 \cdot-$ $0) \leqslant$.

৩. Guidet B, Shah SV. Am J Physiol. 1919; rov $\left(Y^{\tau}\right)$ : F $\varepsilon \varepsilon \cdot$. Cited by Muslih RK, Al- Nimer MS, Al-Zamely OM. The level of malondialdehyde after activation with (HrOr and CuSOs) and inhibition by desferoxamine and molsidomine in the serum of patients with acute myocardial

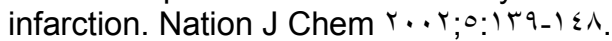

^. Sedlak J, Lindsay RH. Anal. Biochem. 19ч^; 19 r.Cited by Al-Zamely OM, Al-Nimer MS, Al-Muslih RK. Detection the level of peroxynitrite and related with antioxidant status in the serum of patients with acute myocardial infarction. Nation $J$ Chem r... 1; : :Tro-7rv.

१. Butt WR, Blunt SM. The role of the laboratory in the investigation of infertility. Ann. Clin Biochem 1911; $40: 7 \cdot 1-7.9$.

1. Rbertson WG, Marshall RW. Calcium measurments in serum and plasma: Total and ionized. Crit Rev Clin Lab Sci 19v9; $11: r V 1-r \cdot \varepsilon$

11. Nus M, Sa'nchez-Muniz FJ, Sa'nchezMontero JM. A new method for the determination of arylesterase activity in human serum using simulated body fluid. Atherosclerosis... .7 ; $11 \wedge$ : 100_9.

ir. Richmod W. Preparation and properties of a cholesterol oxidase and its application to the enzymatic assay of total cholesterol in serum. Clin Chem 19Vr;19(1 Y): 1 ro.-1 Tor.

1r. Fossati P, Prencipe L. Serum triglycerides determined colorimetrically with an enzyme that produces hydrogen peroxide. Clin Chem $19 \wedge r ; r \wedge(1 \cdot): r \cdot v v$.

I . Kostner G.M. Enzymatic determination in high density lipoprotein fractions prepared by polyanion precipitation. Clin Chem I $9 \vee 7 ;$ YY (0): T9r.

10. Laurence D.R., Bennett PN, Brown MJ.

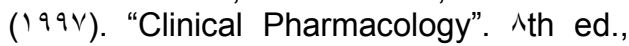
Churchill, Livingstone, London.

17. Steel RGD, Torrie JH. 19^.. Principles and Procedures of Statistics. rnd ed. New York: McGraw-Hill Book Company, Inc. $197 \cdot$ :pp.Av-A., 1.V-1.9, 1 ro-1 rv.

IV. Gerritsen WB, van Boven W-JP, Boss DS, Haas FJ, et al. Malondialdehyde in plasma, a biomarker of global oxidative stress during mini-CABG compared to onand off-pump CABG surgery: a pilot study. Interactive CardioVascular and Thoracic Surgery Y.. T;0:YV_rl.

1^. Asada Y, Komura S, Ohishi N, et al. 199. Effect of ovariectomy on serum lipid peroxide levels in women. $\mathrm{J}$ Clin Biochem Nutr $A: r \leqslant \vee-r o r$.

19. Dolphin, D., Poulson, R. Avromonic, O., Eds. 19^9. In Coenzymes and Cofactors: Gluthathione Chemical, Biochemical and Medical Aspects. Vol r, Part A. New york: Wiley,. (Cited by lantomasi, T., Marraccini, P., Favilli, F., Vincenzini, M.T., Ferretti, P. and Tonelli, F., 199ะ. Glutathione 
metabolism in Crohn's disease. Biochem. Med. Metab. Biol. or: pp.^v_q1).

$r$. Droge, W. Free Radicals in the Physiological Control of Cell Function. r...r; $\wedge$ : pp. $\leqslant V_{-90}$.

Y). Yagi K, Komura S. Inhibitory effect of female hormones on lipid peroxidation. Biochem Int 1917;1 r:1.01-1.00

r. Wassmann S, Bäumer AT, Strehlow K, van Eickels $M$, et al. Endothelial dysfunction and oxidative stress during estrogen deficiency in spontaneously hypertensive rats. Circulation r...1; $1, r$ : $\leqslant r_{0} \leqslant \leqslant 1$.

rr. Massafra C, Buonocore G, Gioia D, Sargentini I, et al. Effects of estradiol and medroxyprogesterone-acetate treatment on erythrocyte antioxidant enzyme activities and malondialdehyde plasma levels in amenorrhoic women. $\mathrm{J}$ Clin Endocrinol Metab 199v;/ r: $/ \mathrm{Vr}_{-} / \mathrm{VO}$

$r$ \&. Höckerstedt A, Jauhiainen M, Tikkanen MJ. Lecithin/cholesterol acyltransferase induces estradiol esterification in highdensity lipoprotein, increasing its antioxidant potential. J Clin Endocrinol

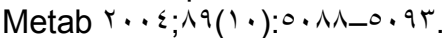

ro. Durrington PN, Mackness B, Mackness MI. Paraoxonase and atherosclerosis. Arterioscler Thromb Vasc Biol $r . .1 ; Y)(\varepsilon)$ : $\varepsilon \vee r-\varepsilon \wedge$.

r.. Watson AD, Berliner JA, Hama SY, La Du BN, Faull KF, Fogelman AM, Navab M. Protective effect of high density lipoprotein associated paraoxonase. Inhibition of the biological activity of minimally oxidized low density lipoprotein. J Clin Invest 1990;97:

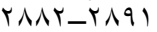

rv. Kumru S, Aydin S, Aras A, Gursu MF, et al. Effects of surgical menopause and estrogen replacement therapy on serum paraoxonase activity and plasma malondialdehyde concentration. Gynecol

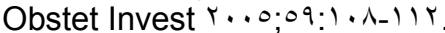

$r \wedge$. Sutherland WHF, Manning PJ, Jong SA, Allum AR, et al. Hormone-replacement therapy increases serum paraoxonase arylesterase activity in diabetic postmenopausal women. Metabolism. r...;:0.(r):rוq_rrs.

rq. Riggs BL, Melton LJ. Involutional

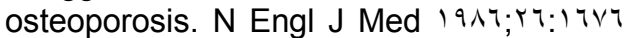
$-171 \leqslant$.

$r \cdot$ Riggs BL, Melton LJ. The prevention and treatment of osteoporosis. $\mathrm{N}$ Engl J Med 199r; rrv: $7 r \cdot-7 r 7$. (Cited by Prestwood $\mathrm{Km}$, Thompson DI, Kenny Am, Seibel Mj, Pilbeam Cc, Raisz Lg. Low dose estrogen and calcium have an additive effect on bone resorption in older women. $\mathrm{J}$ Clin

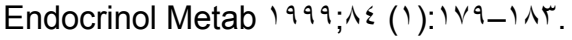

r. Dawson-Hughes B, Dallal GE, Krall EA, Sadowski $L$, et al. A controlled trial of calcium supplementation on bone density in postmenopausal women. $\mathrm{N}$ Engl $\mathrm{J}$ Med $199 \cdot ; r r r: \Lambda V \wedge \_\wedge \wedge r$.

rr. Prestwood Km, Thompson DI, Kenny Am, Seibel $\mathrm{Mj}$, et al. Low dose estrogen and calcium have an additive effect on bone resorption in older women. $\mathrm{J}$ Clin

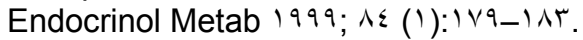

rr. Nordin BE, Horowitz M, Need A, Morris HA. Renal leak of calcium in postmenopausal osteoporosis. Clinical Endocrinology $199 \leqslant ; \leqslant 1: \leqslant 1-\leqslant 0$.

$r \varepsilon$. Cheema C, Grant BF, Marcus R. Effects of estrogen on circulating free and total $1, \mathrm{r}_{-}$ dihydroxyvitamin $D$ and on the parathyroid-vitamin $D$ axis in postmenopausal women. J Clin Invest 1919; ᄉr: orv_o

ro. Napoli N, Thompson J, Civitelli R, Armamento-Villareal RC. Effects of dietary calcium compared with calcium supplements on estrogen metabolism and bone mineral density. Am J Clin Nutr

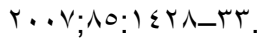

rч. Itoh M, Oh-ishi S, Hatao H, Leeuwenburgh $\mathrm{C}$, et al. Effects of dietary calcium restriction and acute exercise on the antioxidant enzyme system and oxidative stress in rat diaphragm. Am $\mathrm{J}$ Physiol Regul Integr Comp Physiol $r \ldots \xi ; r \wedge \vee$ : Rrr-RrN.

rv. Bush TL. The epidemiology of cardiovascular disease in postmenopausal women. Ann New York Acad Sci 199.; O9Y: YTr-YVI.

ґ^. Stampfer MJ, Colditz GA, Willett WC, Manson JE, et al. Postmenopausal estrogen therapy and cardiovascular disease. Ten year follow-up from the Nurses Health Study. N Engl J Med 1991;rro:vor_vir.

ч . Seed M. Sex hormones, lipoproteins, and cardiovascular risk. Atherosclerosis 1991; $q \cdot: 1-v$.

¿. Subbiah MTR. Mechanisms of cardioprotection by estrogens. Proc Soc Exper Biol Med 199ᄉ; $r$ । $\vee: r r \_r q$.

«. Tang M, Subbiah MTR. Estrogens protect against hydrogen peroxide and arachidonic acid induced DNA damage. Bioch Biophys Acta 1997; 1 Y99:100-109.

$\varepsilon r$. Ayers S, Abplanalp W, Liu JH, Subbiah MTR. Mechanisms involved in the protective effect of estradiol- $I \vee \beta$ on lipid peroxidation and DNA damage. Am J

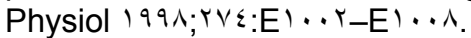


Irq $J$ Pharm Vol. ${ }^{9} \& 1 \cdot$, No. ' ,

r. I.

\&r. Abplanalp W, Scheiber MD, Moon K, Kessel B, et al. Evidence for the role of high density lipoproteins in mediating the antioxidant effect of estrogens. Europ $\mathrm{J}$ Endocrinol $r \cdots ;$; $\leqslant r$ : $\vee q_{-} \wedge r$.

« ₹. Ferretti G, Bacchetti T, Busni D, Rabini RA, et al. Protective Effect of paraoxonase activity in high-density lipoproteins against erythrocyte membranes peroxidation: A comparison between healthy subjects and type 1 diabetic patients. J Clin Endocrinol

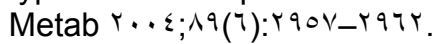

